\title{
DCEP/Bortezomib Regimen
}

National Cancer Institute

\section{Source}

National Cancer Institute. DCEP/Bortezomib Regimen. NCI Thesaurus. Code C160566.

A chemotherapy regimen consisting of bortezomib, dexamethasone, cyclophosphamide, etoposide, and cisplatin that can be used in the treatment of plasma cell (multiple) myeloma. 